\title{
MACROFOTOGRAFÍA: RECURSO VISUAL PARA DOCUMENTAR ALGUNOS INSECTOS PRESENTES EN EL MUNICIPIO DE QUIPILE, CUNDINAMARCA
}

\section{Macrophotography As a Visual Resource to Document some Insects Found in the Municipality of Quipile, Cundinamarca}

\section{A Macrofotografia como recurso para saber e ensinar a biodiversidade de insetos presentes no município de Quipile, Cundinamarca}

\section{Ricardo Martínez Gamba ${ }^{1}$ Lorena Guerrero Félix ${ }^{2}$}

Fecha de recepción: 20 de septiembre de 2017

Fecha de aceptación: $1 .^{\circ}$ de junio de 2018

\section{Introducción}

Los insectos son los organismos más exitosos sobre la tierra, constituyen más de las tres cuartas partes de la vida conocida en el planeta (Wolff, 2006). En Colombia se han descrito más de 15000 especies, equivalentes al $10 \%$ de las que en realidad se cree que existen (Global Biodiversity Information Facility [GBIF] (citado en Sistema Integrado de Biodiversidad Colombia [SIB Colombia], 2016)). Su abundancia, diversidad y distribución se atribuyen no solo a su morfología, que ha tenido grandes adaptaciones, sino también, a las relaciones tan estrechas que han establecido con otros organismos. Prácticamente no existe un solo organismo en la tierra, sésil o no, que no posea un insecto como asociado histórico (Wolff, 2006), lo que los ha convertido en importantes agentes polinizadores, controladores biológicos, recicladores de nutrientes, entre otros (Blas y Del Hoyo, 2013).

Sin embargo, los insectos han sido estereotipados, reconocidos como plagas y agentes patógenos por las personas del común. Se trata de una visión reduccionista e incluso errónea; por ello, durante los últimos años se ha dado una

1 Biólogo, magíster en Desarrollo Sustentable y Gestión Ambiental, Universidad Distrital Francisco José de Caldas. Grupo de Investigación Cascada, Universidad Pedagógica Nacional. Correo electrónico: rmartinezg@pedagogica.edu.co.

2 Licenciada en Biología, línea de investigación Biodiversidad, Biotecnología y Conservación, Universidad Pedagógica Nacional. Correo electrónico: dbi_jlguerrerof891@pedagogica.edu.co. 


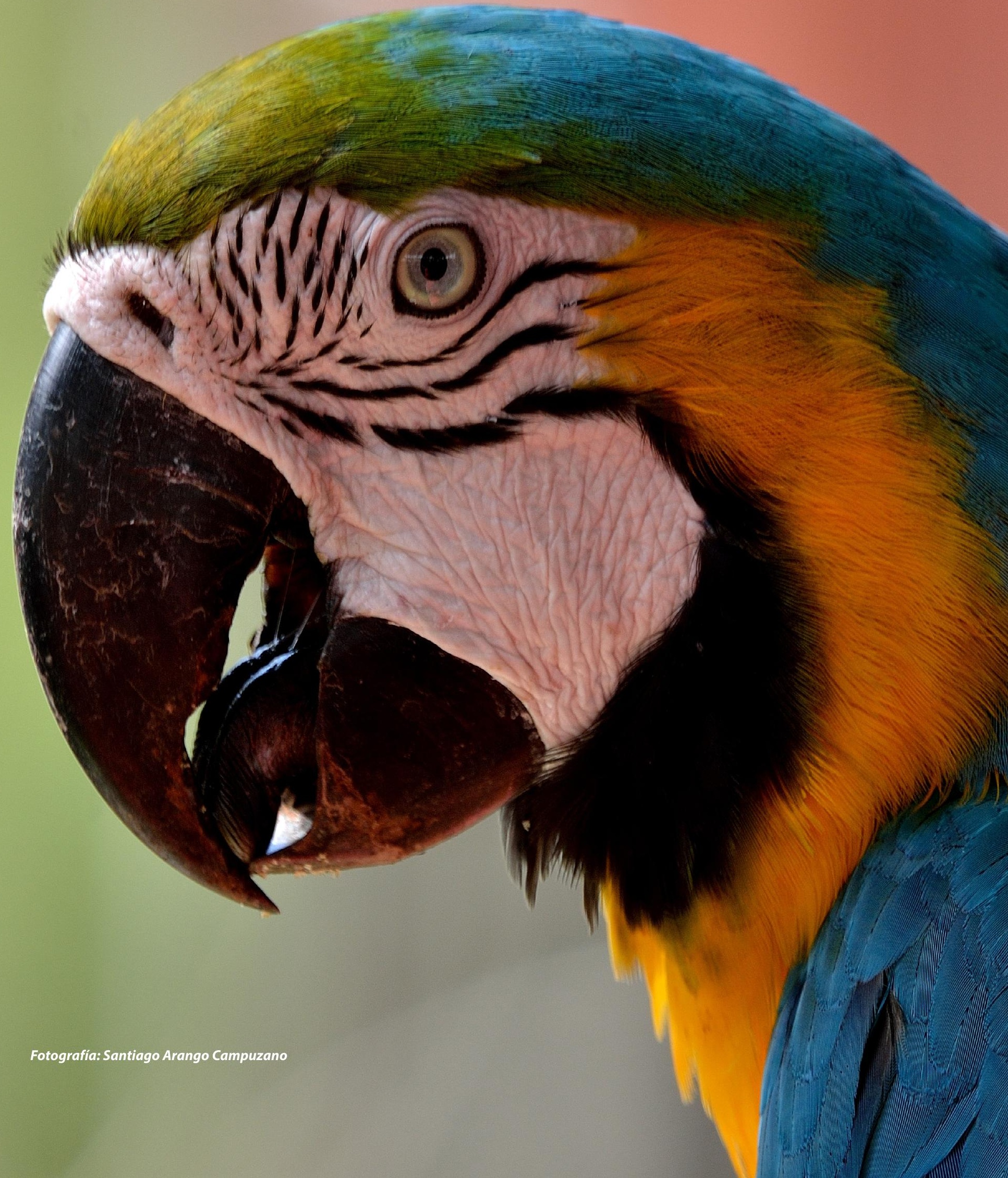


falta de interés y desconocimiento de su importancia biológica (Torres, 2014). Por esta razón, se empleó la macrofotografía, para enriquecer el conocimiento sobre la entomofauna local, teniendo en cuenta que como recurso visual permitió documentar algunos insectos presentes en los cultivos de café del municipio de Quipile, Cundinamarca, y con ello aportar a la solución de la problemática mencionada.

Este municipio se encuentra ubicado en el suroccidente del departamento de Cundinamarca, sobre la Cordillera Oriental. Tiene una extensión de aproximadamente 12760 hectáreas, con altitudes entre 1599 y 1702 metros sobre el nivel del mar, temperaturas de 16 a $18^{\circ} \mathrm{C}$ y precipitaciones de 1000 a 2000 mm (Alcaldía de Quipile, 2012). La zona estudiada fue la vereda Guadalupe alto, que forma parte del bosque húmedo premontano y se constituye en una transición entre el trópico y los ambientes de alta montaña, razón por la cual comparte una buena proporción de sus especies con ambas formaciones vegetales (Rodríguez, Armenteras, Morales y Romero, 2006). En ella encontramos cultivos de café (Coffe arábica L.) asociados a una vegetación forestal (como: Ocobo [Tabebuia rosea (Bertol.)],Guamo [Inga sp.], Yarumo [Cecropia sp.] e Higuerón [Ficus sp.]) y agrícola (como cítrico [Citrus sp.], plátano (Musa sp.), guayaba (Psidium sp.) y aguacate [Persea americana]), Mill., 1768). Estos lugares coinciden con zonas con gran cantidad de biodiversidad, y se asemejan a los bosques y parches de bosques; generan una gran cantidad de hábitats a diferentes grupos de artrópodos benéficos para loscultivos, donde se presentan una variedad de interacciones complejas que generan un equilibrio ecosistémico (Perfecto, Vandermeer y Philpott, 2010; Sinisterra, Gallego-Ropero y Armbrecht, 2016).

Por lo anterior, y producto de las prácticas de campo realizadas entre los meses de julio de 2016 y abril de 2017 para la tesis de maestría: Relaciones socioecológicas entre hormigas y agricultores como estrategia sustentable en cafetales de sombrío (Quipile, Cundinamarca) (Martínez, 2018), se decidió emplear la macrofotografía para documentar algunos insectos presentes en los cultivos de café de cuatro fincas de dicho municipio.

Se aprecia como la macrofotografía, además de facilitar la captura de un momento específico, permite documentar estudios relacionados con muchas especies, mostrando al detalle cosas que no se pueden observar a simple vista (Pérez, 2012). Esto la convierte en el recurso adecuado para conocery enseñar la gran biodiversidad de estos pequeños organismos tan importantes para el mundo: los insectos.
En estas macrofotografías, además de reconocer los insectos y determinar su familia, tribu, género o incluso especie, se aprecian relaciones ecológicas y comportamientos específicos plantas-insectos e insecto-insecto. Las fotografías se tomaron con una cámara Nikon D5200 y empleando un lente macro tamron $90 \mathrm{SP} \mathrm{mm} \mathrm{F/2.5,} \mathrm{se} \mathrm{espera} \mathrm{que} \mathrm{con} \mathrm{estas}$ imágenes se reivindique este recurso como una alternativa para conocer la gran biodiversidad de nuestro país.

\section{Lepidóptera}

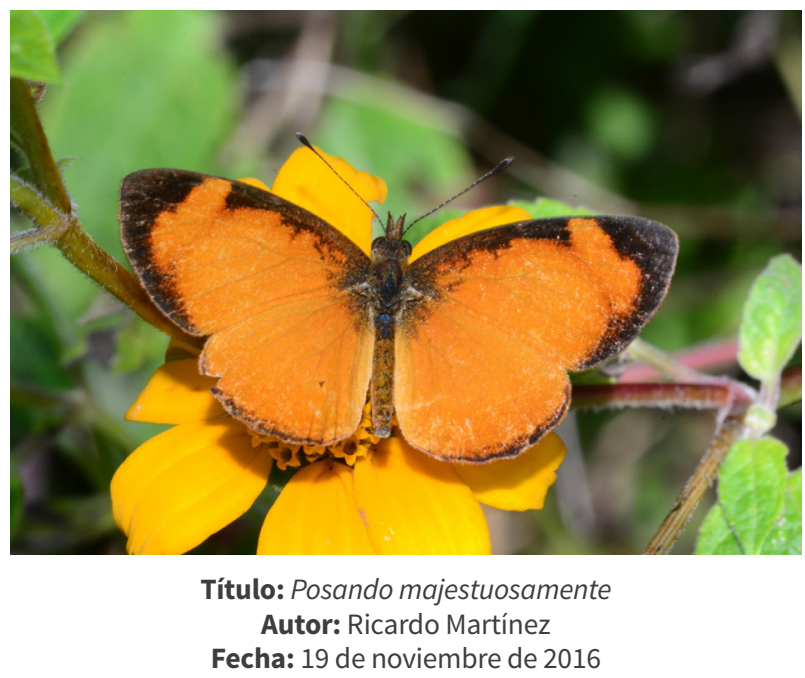

La especie Tegosa anieta (Hetwitson, 1864) se posa sobre una flor. La distribución de los colores naranja y negro la hacen una de las más llamativas, además de que es bastante tranquila. Esto permite acercarse lo suficiente para observar su comportamiento y su magnífica morfología. 


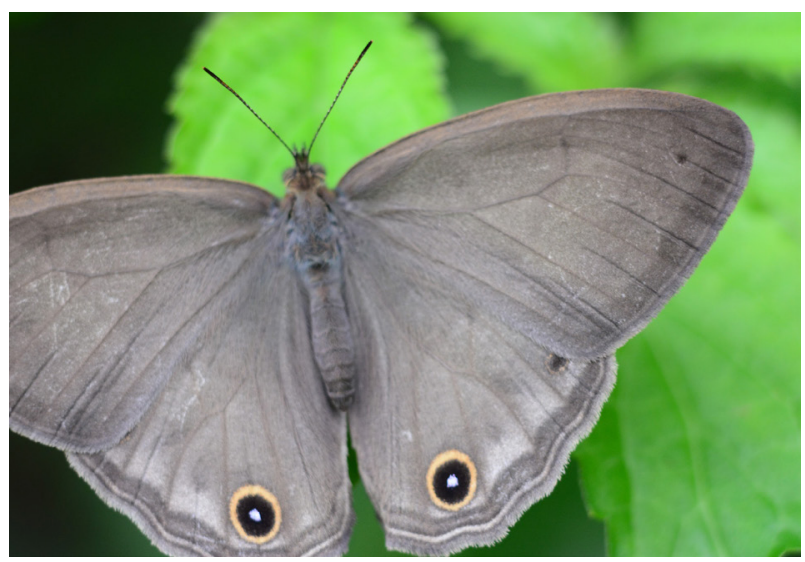

Título: Ojos vigilantes

Autora: Lorena Guerrero

Fecha: 19 de noviembre de 2016

Esta mariposa del género Cissia sp. Las características manchas que poseen en sus alas simulan la forma de unos hermosos ojos, logran causar la impresión de que con ellos estuviera observando fijamente a quien se le acerque, obligándolo a permanecer bajo asombro al ver tan espectacular mariposa.

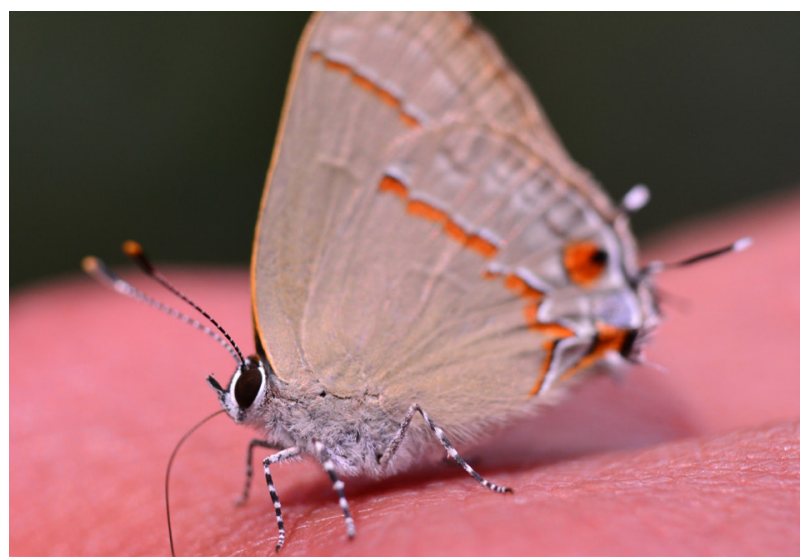

Título: De otro mundo

Autor: Ricardo Martínez

Fecha: 28 de julio de 2016

Esta bella mariposa del género Strymon $s p$. pareciera ser de otro mundo. Posee características únicas, por ejemplo, el apéndice en forma de cuerno ubicado en su cabeza y la terminación de sus alas, que asemejan la forma de una antena. Esto le permite confundir a sus depredadores sobre la posición real de su cuerpo.

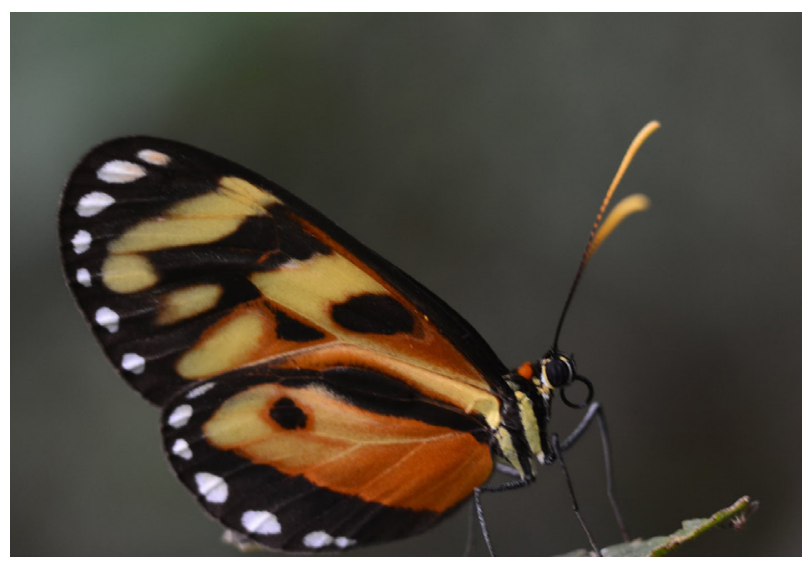

Título: Obra de arte

Autor: Ricardo Martínez

Fecha: 28 de julio de 2016

Es común encontrar la especie Ithomia iphianassa (Doubleday, 1947). Con una coloración aposemática, en los cafetales de sombrío de Quipile volando con especies miméticas. Generalmente se alimenta de néctar de flores, se puede observar la tranquilidad con la que se posa sobre una planta, como si se tratara de una pintura.
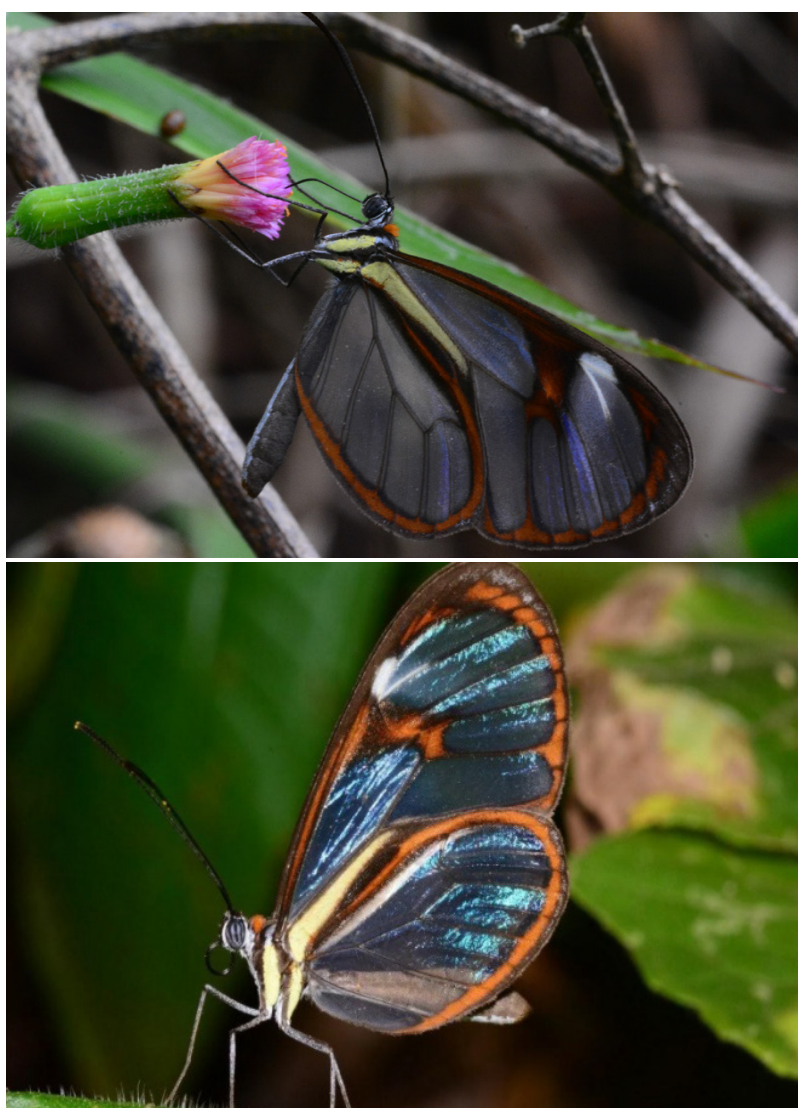

Título: Alas de cristal

Autora: Lorena Guerrero

Fecha: 9 de abril de 2017 
Esta mariposa, comúnmente conocida como "alas de cristal", por la transparencia de sus alas, pertenece a la tribu Ithomiinae y posee hábitos solitarios o gregarios. En esta oportunidad fue encontrada alimentándose del néctar de una flor.

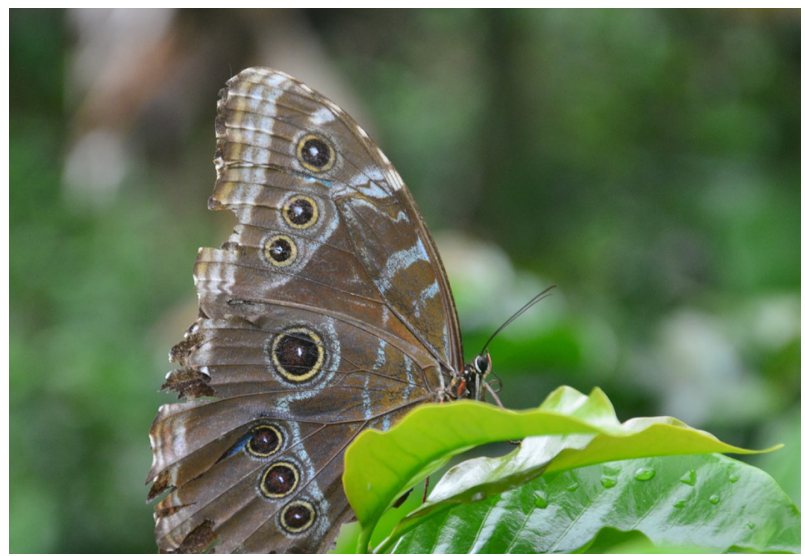

Título: Las heridas de la vida

Autora: Lorena Guerrero

Fecha: 28 de octubre de 2016

Este ejemplar de Morpho sp., a pesar de sus alas ya desgastadas y rotas, no deja de deleitarnos con su gran tamaño y variedad de colores. En sus alas podemos encontrar desde un color café con amarillo, hasta un intenso color azul metalizado; su vuelo poderoso, lento y ondulante acompaña los senderos y caminos de los cafetales de Quipile.

\section{Coleóptera}

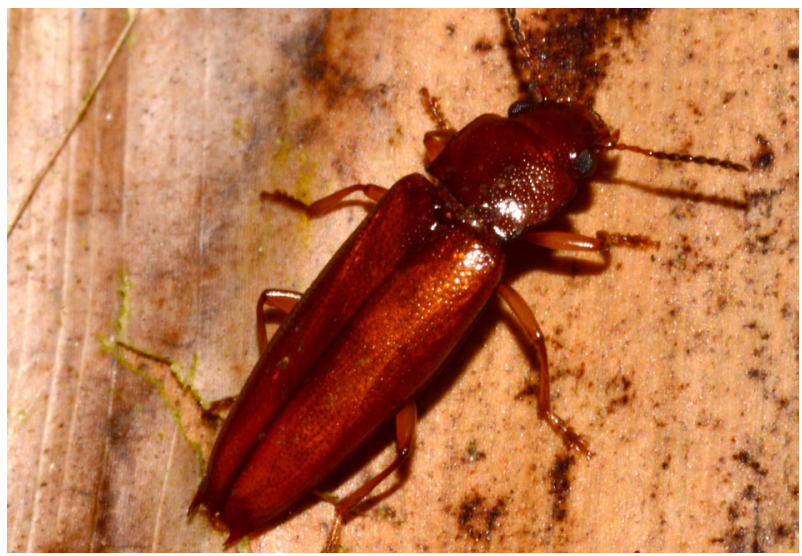

Título: Al acecho

Autor: Ricardo Martínez

Fecha: 12 de noviembre de 2016

Este Cucujidae, caracterizado por poseer el cuerpo plano, generalmente de color marrón rojizo, habita en la corteza de los árboles. Se encuentra esperando a su presa, por lo cual pareciera pasar desapercibido.

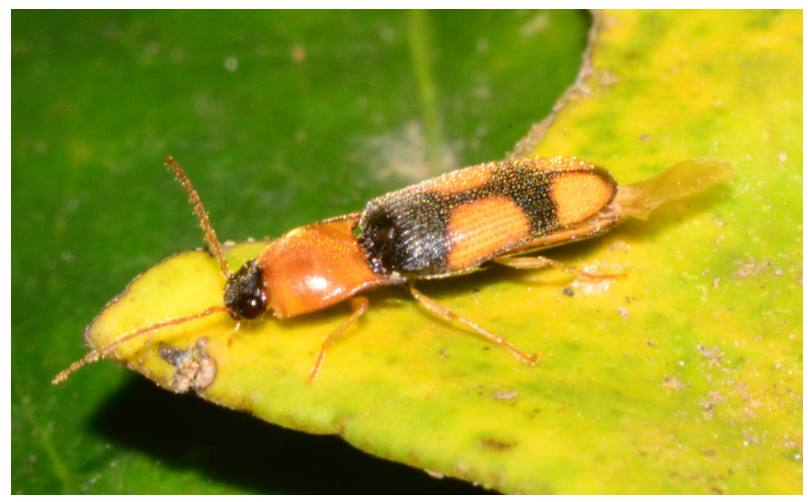

Título: El saltador

Autora: Lorena Guerrero

Fecha: 9 de abril de 2017

Los Elateridae se caracterizan por producir un sonido parecido a un clic, que les funciona para salir volando o erguirse cuando se encuentran boca arriba. Son estrictamente nocturnos. Este se encuentra sobre una hoja, atraído por la luz de la cámara.

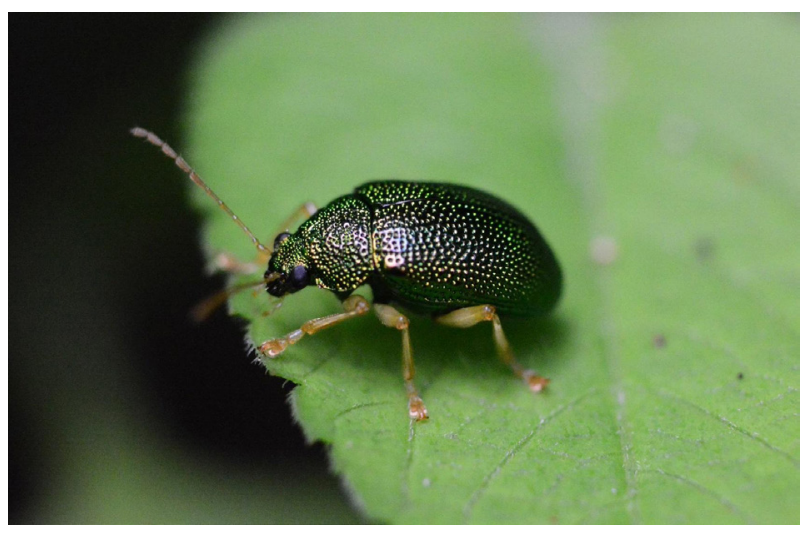

Título: Apariencia engañosa

Autora: Lorena Guerrero

Fecha: 10 de abril de 2017

Esta especie de cucarrón Colaspis lebasi (Lefèvre,1878). De color verde brillante, con orificios por todo su cuerpo, se encuentra en posición para depredar una hoja. Es considerado una plaga importante para algunas especies cultivadas, aunque su apariencia es inofensiva. 


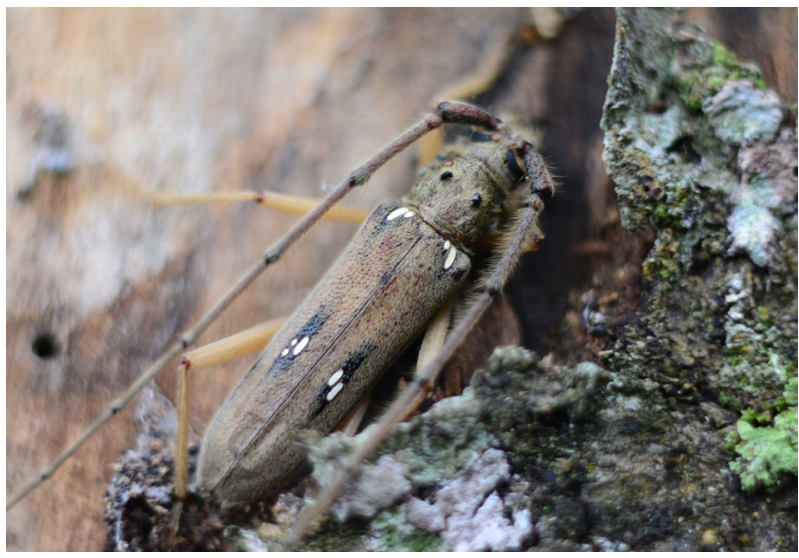

Título: Mimetismo

Autora: Lorena Guerrero

Fecha: 19 de noviembre de 2016

Este insecto del género Eburia sp. pasa desapercibido por el camuflaje o cripsis, que le otorga el color y textura de su cuerpo, se posa en el tronco de un árbol y, silencioso e inmóvil, evita ser devorado por algún depredador; también captura sus presas sigilosamente.

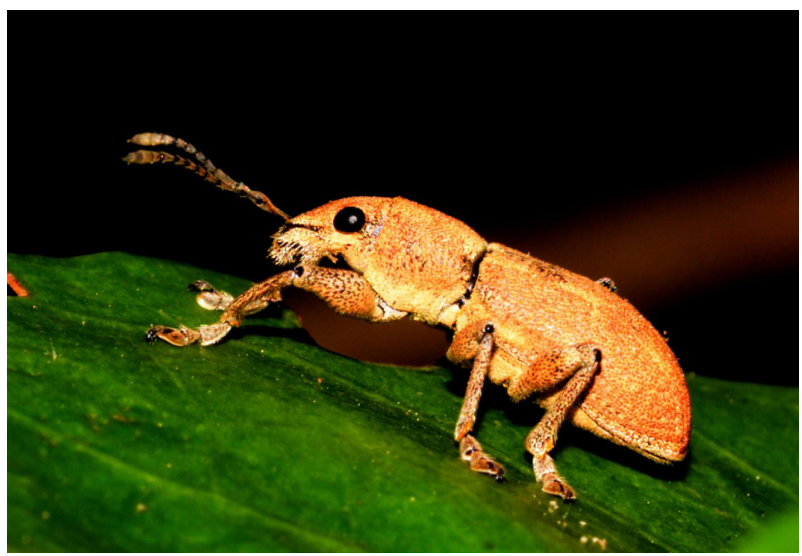

Título: Picudo de trompa corta

Autora: Lorena Guerrero

Fecha: 9 de abril de 2017

Los Naupactini son gorgojos fitófagos, muy tranquilos. A diferencia de otras tribus de esta misma familia, no presenta su aparato bucal alargado. Pueden llegar a considerarse plaga de cultivos.

\section{Hymenoptera}

Familia: Formicidae

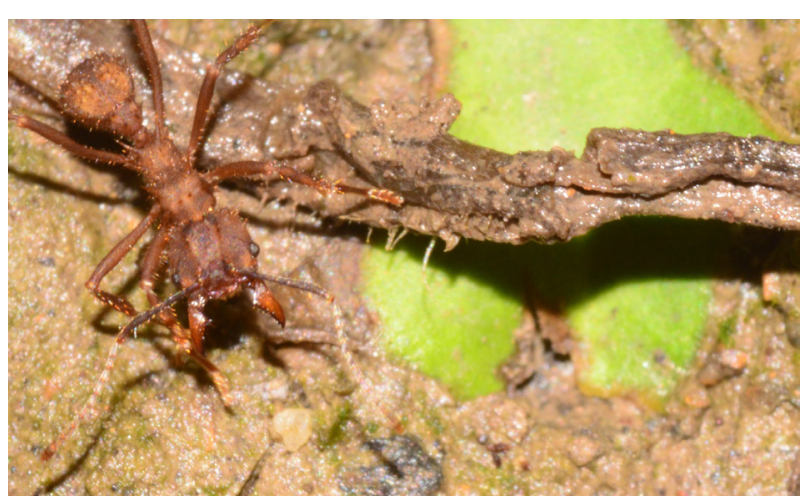

Título: Cortadora de hojas

Autor: Ricardo Martínez

Fecha: 9 de abril de 2017

La famosa hormiga arriera o cortadora de hojas con uno de sus representantes, la especie Acromyrmex hystrix (Latreille, 1802). Llama la atención porque hace grandes caminos. Además de su polimorfismo, cortan las hojas con sus potentes mandíbulas y las transportan a su colonia; en gran cantidad se pueden considerar una plaga.

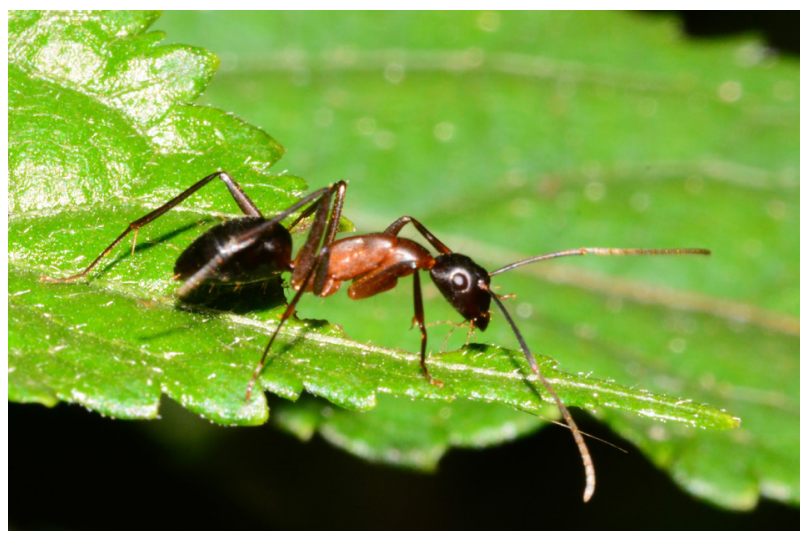

Título: Carpintera

Autor: Ricardo Martínez

Fecha: 9 de abril de 2017

Esta especie, conocida como hormiga carpintera Camponotus simillimus (Smith, 1862) hace sus nidos en árboles, o entre las hojas. Aparentemente está buscando alguna fuente de alimento; al encontrarla, por medio de señales químicas alerta a sus compañeras. 


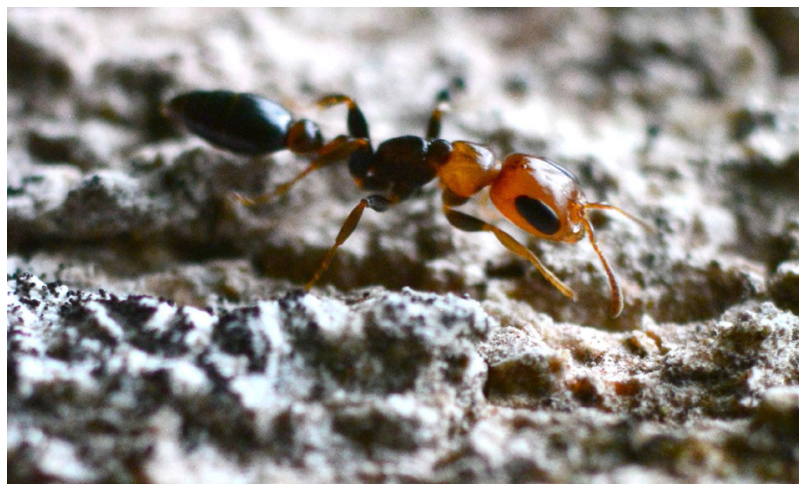

Título: Vertiginosa arbórea Autor: Ricardo Martínez

Fecha: 19 de noviembre de 2016

Esta bella hormiga estrictamente arbórea pertenece al género Pseudomyrmex sp. Además de su vistoso color, resultan ser hormigas muy ágiles y difíciles de observar, que bajan de los árboles a depredar en la vegetación. La de la fotografía se encuentra alerta ante cualquier depredador.

\section{Phasmatodea}

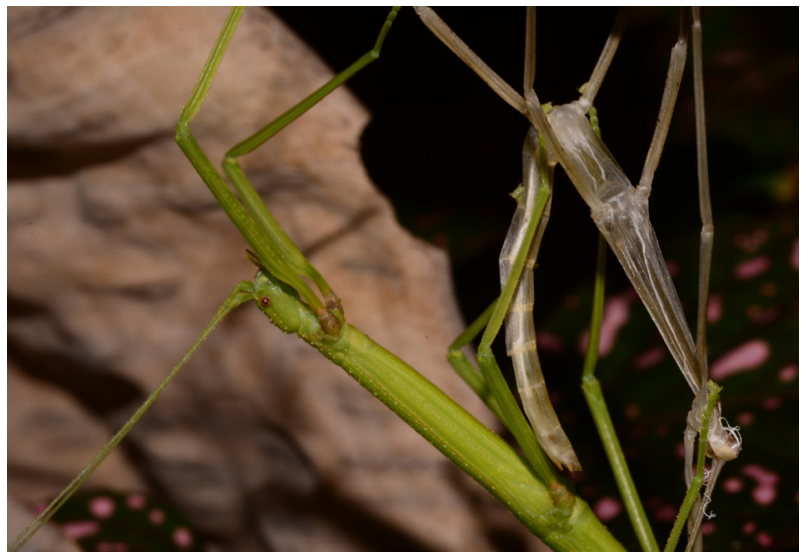

Título: Ecdisis

Autor: Ricardo Martínez

Fecha: 12 de noviembre de 2016

La ecdisis es el proceso mediante el cual muchos organismos, entre ellos los insectos, mudan o renuevan su tegumento o exoesqueleto, para permitir el crecimiento del organismo. En esta fotografía podemos observar a un individuo del género Libethra sp., con su exuvia recién mudada enredada en las patas.

\section{Hemíptera}

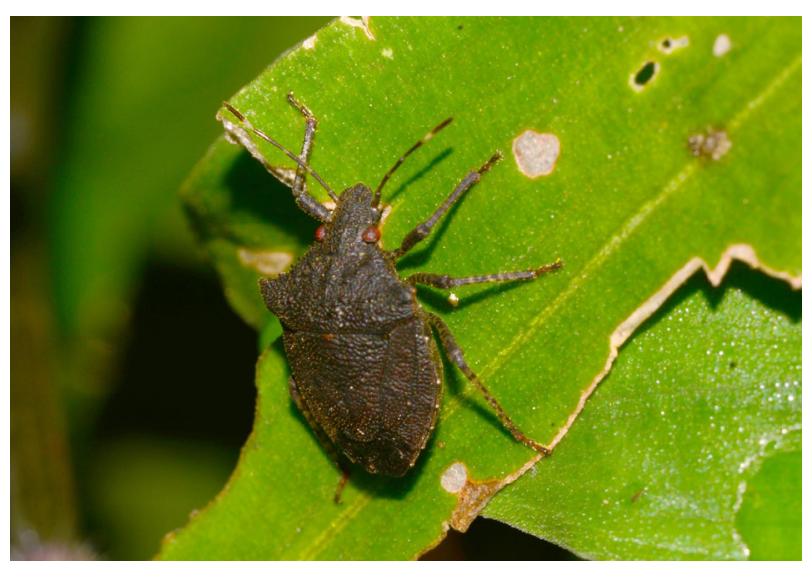

Título: Chinche escudo

Autora: Lorena Guerrero

Fecha: 12 de noviembre de 2016

Este hemíptero del género Euschistus sp., caracterizado por la forma de escudo de su cuerpo, es fitófago. Cuando se encuentran muchos individuos de este género pueden causar problemas de importancia económica en cultivos; cuando son pocos, pueden ayudar a regular el crecimiento de la planta.

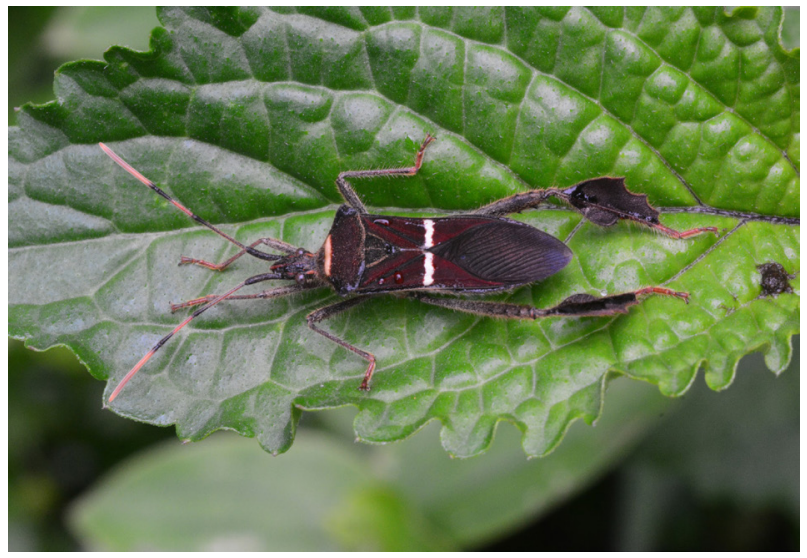

Título: Patas de hoja

Autora: Lorena Guerrero

Fecha: 10 de abril de 2017

Los Leptoglossus sp., al igual que varios individuos de la familia Coreidae se caracterizan por la peculiar forma de su tibia, que se asemeja a una hoja. Este rasgo inevitablemente los convierte en uno de los hemípteros más llamativos; podemos observar cómo se alimenta de la savia de la planta hospedera. Este insecto puede ser de interés económico, ya que es plaga representativa de algunos cultivos. 


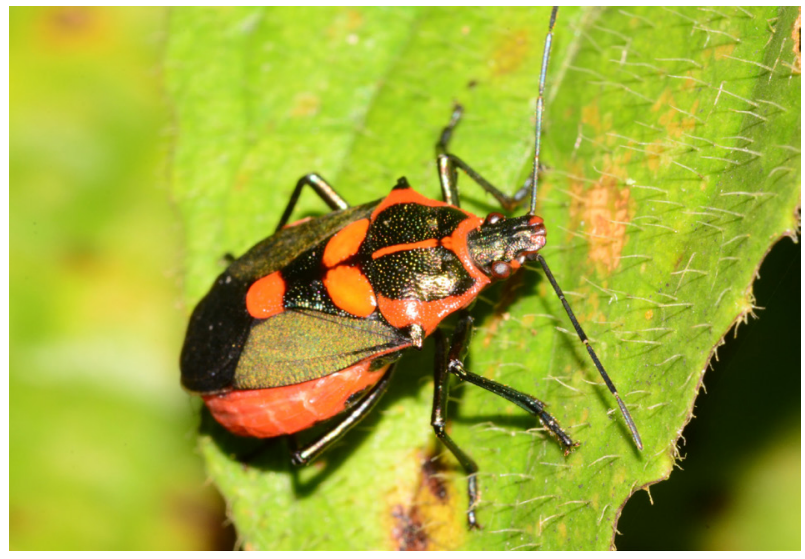

Autor: Ricardo Martínez

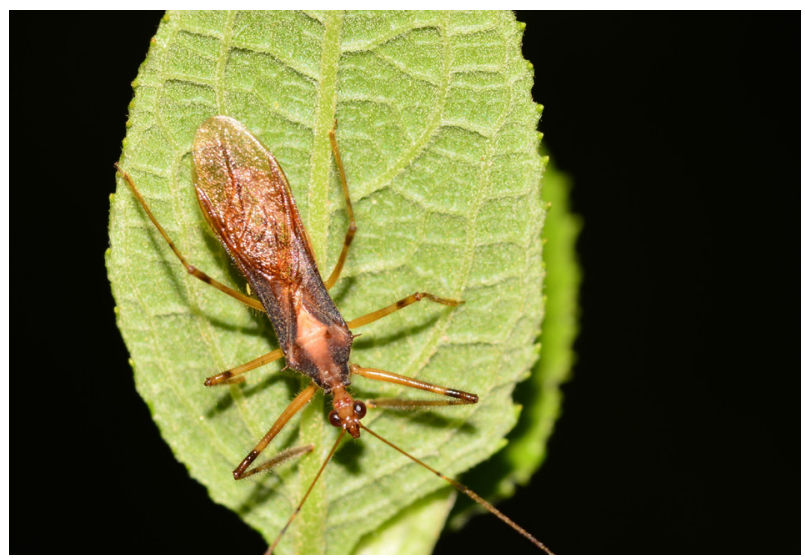

Título: Visitantes nocturnos

Autor: Ricardo Martínez

Fecha: 9 de abril de 2017

En una de las salidas nocturnas realizadas, nos encontramos con Eurydema sp. (imagen A) y Alydidae (imagen B), pertenecientes a los hemípteros fitófagos, pueden ser de importancia económica en cultivos, siempre y cuando sean abundantes, de lo contrario no son perjudiciales.

\section{Blattodea}

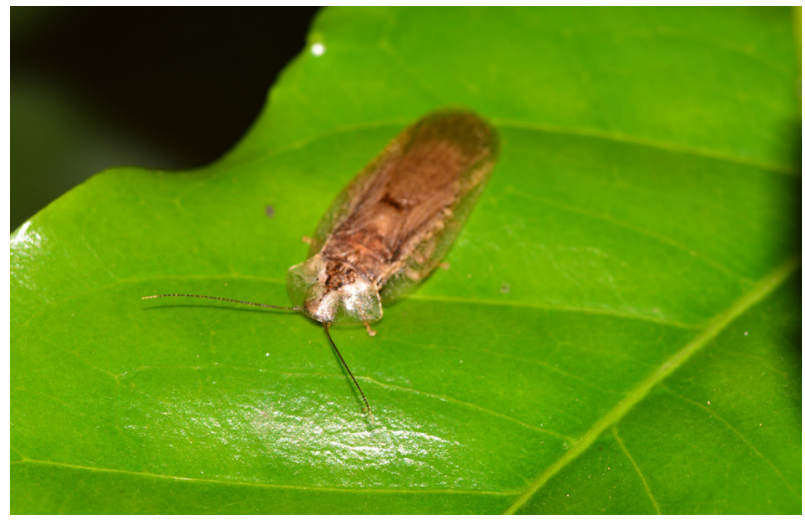

Autor: Ricardo Martínez

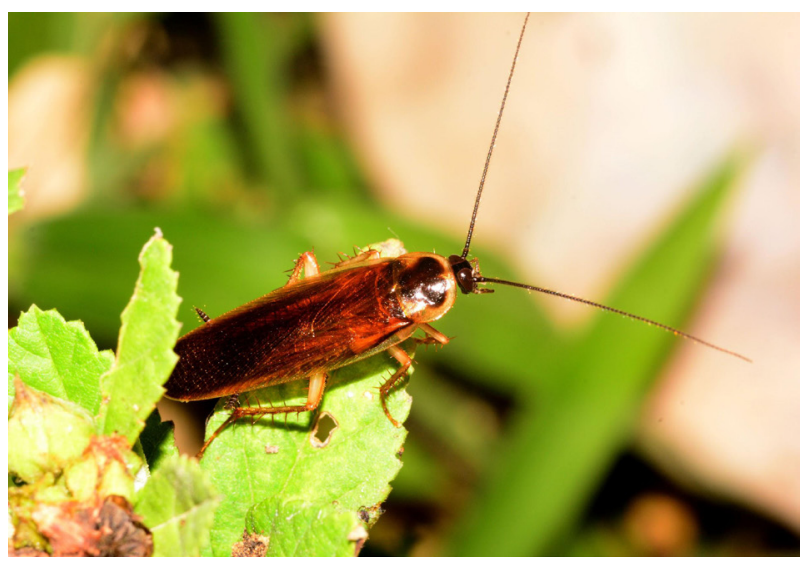

Título: Recicladores de desperdicios

Autora: Lorena Guerrero

Fecha: 5 de noviembre de 2016

Las cucarachas son de los insectos más estereotipados por su aspecto, y su rapidez en el momento de caminar y volar. También se las asocia a desperdicios y suciedad, pero en realidad tienen una importancia ecológica invaluable, ya que contribuyen al ciclo del nitrógeno, tomando la materia en descomposición y convirtiéndola en productos aprovechados por las plantas, podemos observar a Blaberidae (imagen A) y Periplaneta sp. (imagen B) pertenecientes a tan importante orden. 


\section{Hymenoptera}

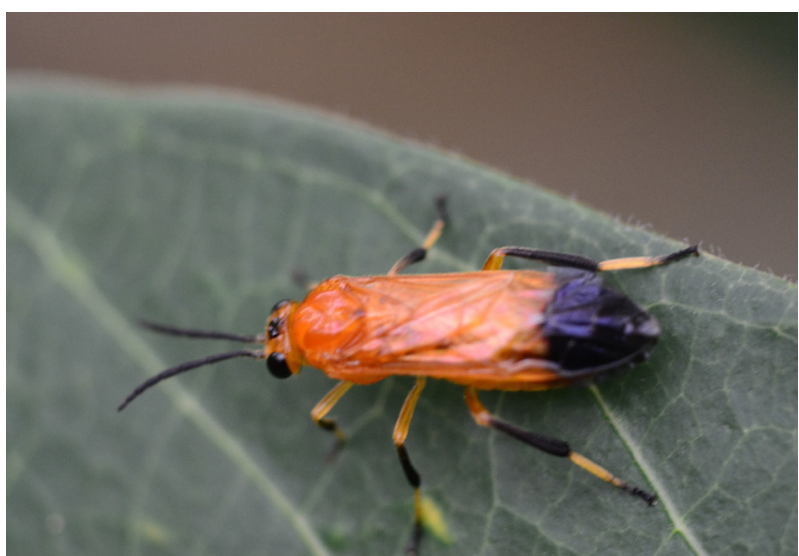

Título: Comedor de hojas

Autor: Ricardo Martínez

Fecha: 19 de noviembre de 2016

Este Hymenoptera de la familia Tenthredinidae en su estado larval es comedor de hojas de diferentes especies de plantas. Se alimenta de estas hasta llegar a su estado adulto. En la imagen se ve a un individuo posado sobre una hoja, posiblemente para depositar sus huevos e iniciar un nuevo ciclo de vida.

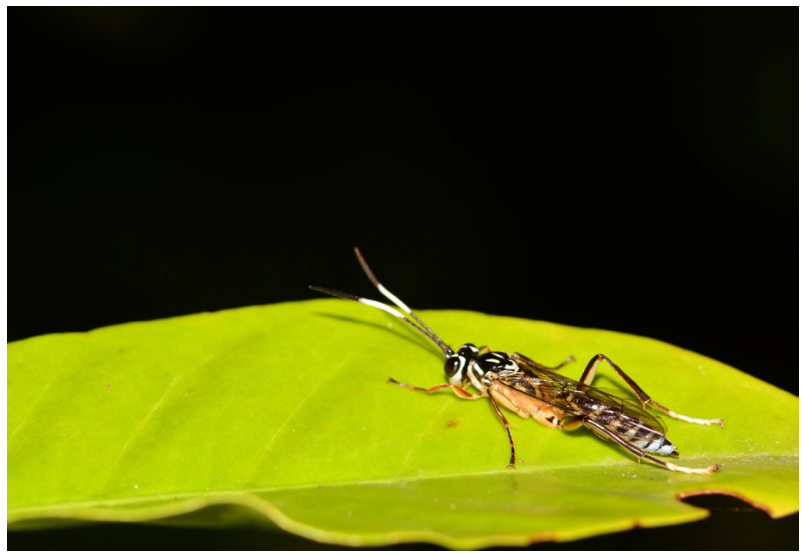

Título: Parasitoide

Autora: Lorena Guerrero

Fecha: 5 de noviembre de 2016

El parasitismo es común entre insectos y otros artrópodos. La mayoría de parasitoides pertenecen al orden Hymenoptera como es el caso del género Cryptanura sp., quienes depositan sus huevos dentro de sus huéspedes y se alimentan de ellos hasta causarles la muerte. Esta función permite regular las poblaciones en el ecosistema, por ello se les considera controladores biológicos.

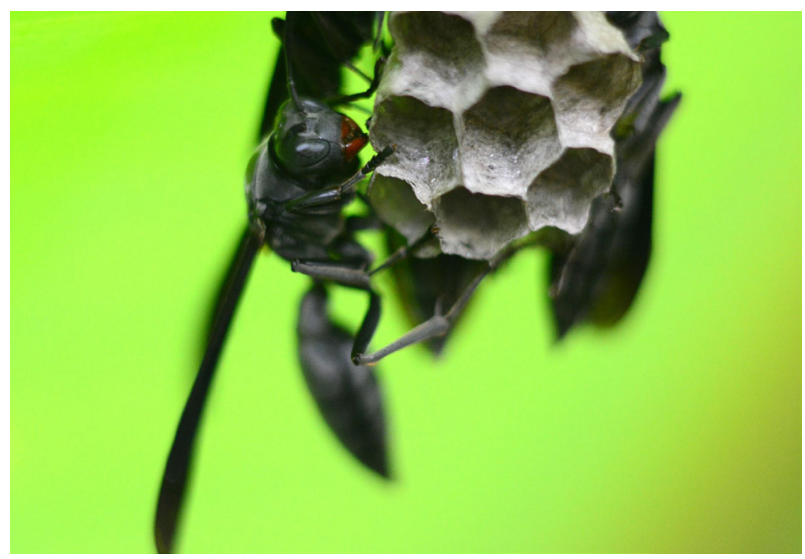

Título: Avispa papelera

Autor: Ricardo Martínez

Fecha: 19 de noviembre de 2016

Esta avispa del género Polistes sp. se caracteriza por hacer su nido con papel o cartón. Estas avispas son depredadoras y visitantes de flores. En la imagen se evidencia la construcción del nido por parte de las integrantes de la colonia, quienes por su imponente escultura dan señal de amenaza.

\section{Ortóptera}

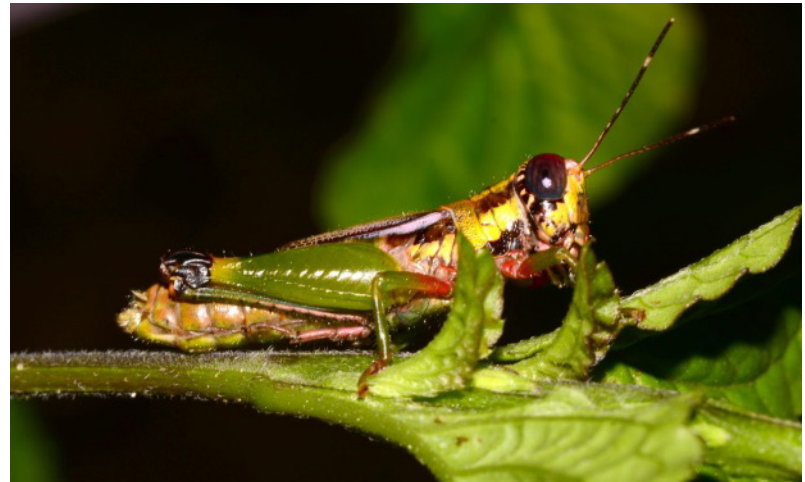

Fecha: 12 de noviembre de 2016

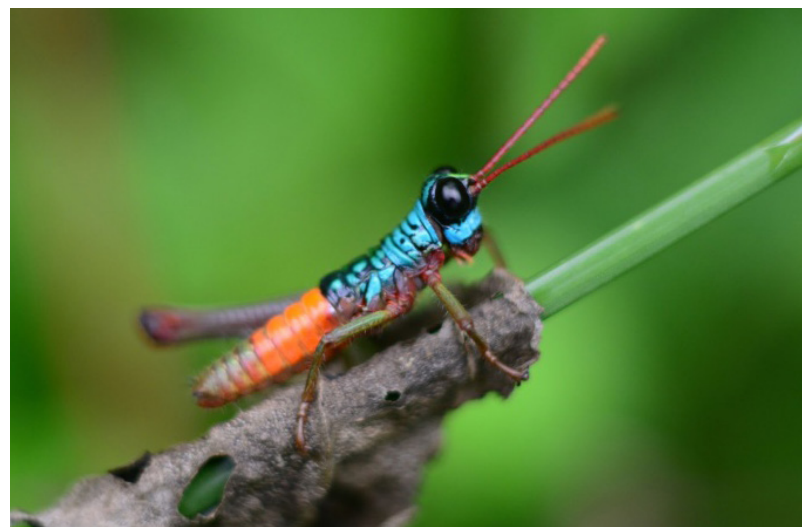

Título: Colores llamativos

Autora: Lorena Guerrero

Fecha: 9 de abril de 2017 
Entre los insectos más abundantes y diversos de Quipile encontramos a los grillos y saltamontes, que muchas veces por su pequeño tamaño ignoramos. Sin embargo, Taeniophora sp (imagen A) y Opanoella tenuis (Herbad, 1923) (imagen B) no pasan desapercibidos por sus hermosos y llamativos colores; se posan sutilmente esperando cualquier movimiento en falso para saltar con sus imponentes patas traseras y huir.

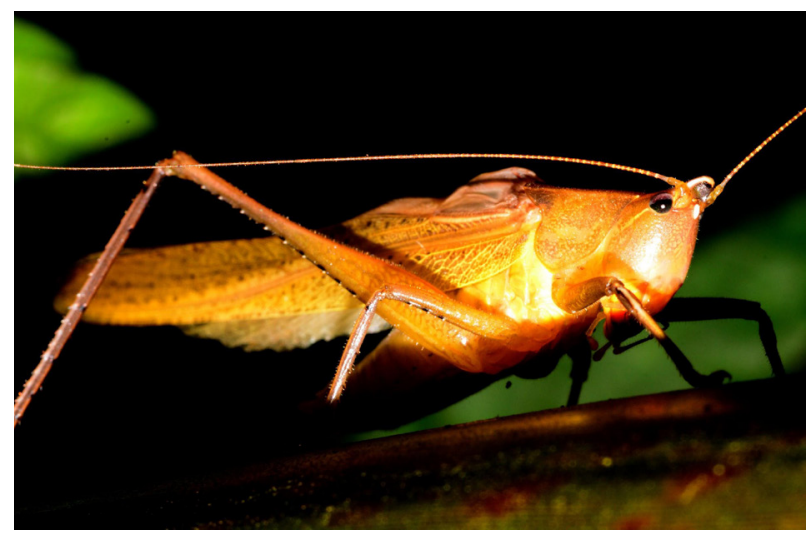

Título: Gigante nocturno

Autora: Lorena Guerrero

Fecha: 9 de abril de 2017

En la noche, bajo la rama de un árbol encontramos un individuo muy peculiar de la especie Neoconocephalus affinis (Palisot de Beauvois, 1805), cuyo gran tamaño llamó nuestra atención. Es de hábito nocturno, tiene movimientos muy lentos y se alimenta de plantas.

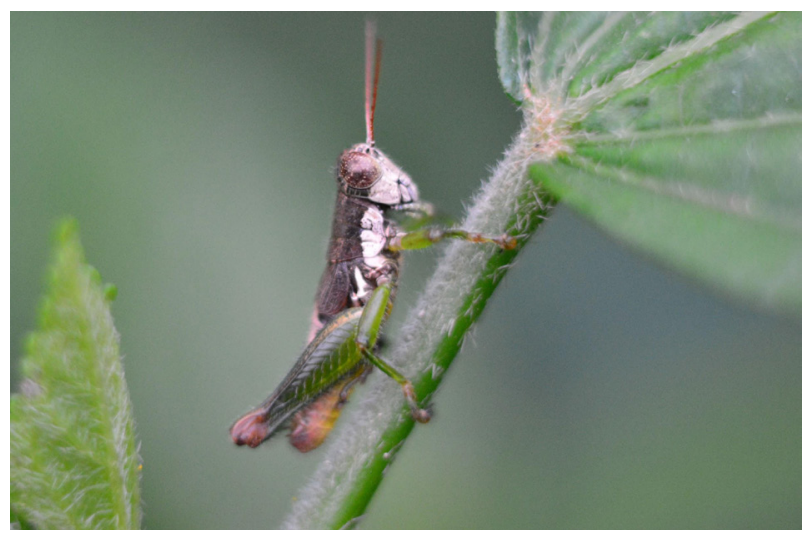

Título: Oculto en los cafetales Autor: Ricardo Martínez

Fecha: 5 de noviembre de 2016

Este pequeño Ciglianacris submontana, recientemente descrito como nuevo género y nueva especie (Cadena-Castañeda y Cardona, 2017), gracias a sus características morfológicas, está presente en cafetales de sombrío, con lo que podemos resaltar la gran diversidad de saltamontes que se pueden encontrar en estos agroecosistemas.

\section{Simbiosis mutualista entre insectos}

Una de las interacciones biológicas más fascinante es el mutualismo. Gracias a él, dos o más especies pueden beneficiarse mutuamente; por ejemplo, el género Myzus sp. Se caracteriza por ser una plaga de cultivos, sin embargo, al relacionarse con otros insectos, como Agelaia areata (Say, 1837) (imagen A) y Procryptocerus scabriusculus (Forel, 1899) (imagen C), se puede controlar y evitar que cause daños en las cosechas, al mismo tiempo que es protegido de depredadores. A cambio, brinda un exudado azucarado a sus protectores, quienes se alimentan de él. De la misma forma, Linepithema sp. Y Entylia sp (imagen B) se relacionan y se benefician el uno del otro.

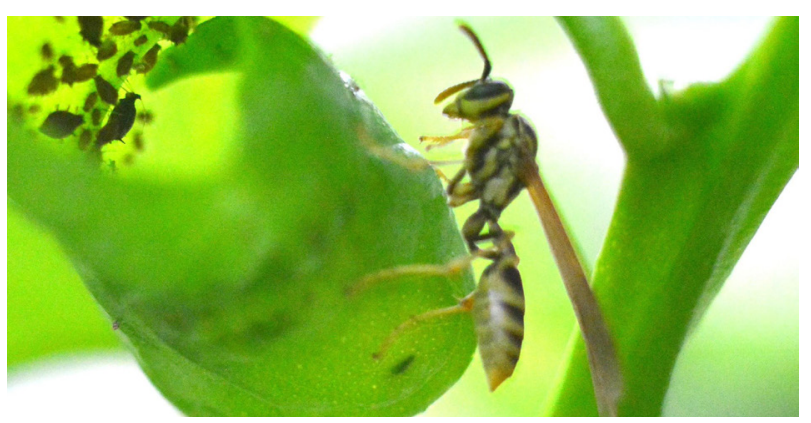

Autor: Ricardo Martínez

Fecha: 29 de octubre de 2016

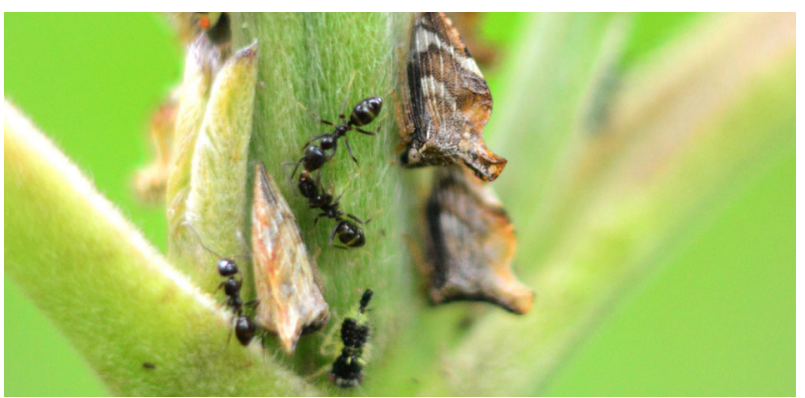

Autora: Lorena Guerrero

Fecha: 9 de abril de 2017

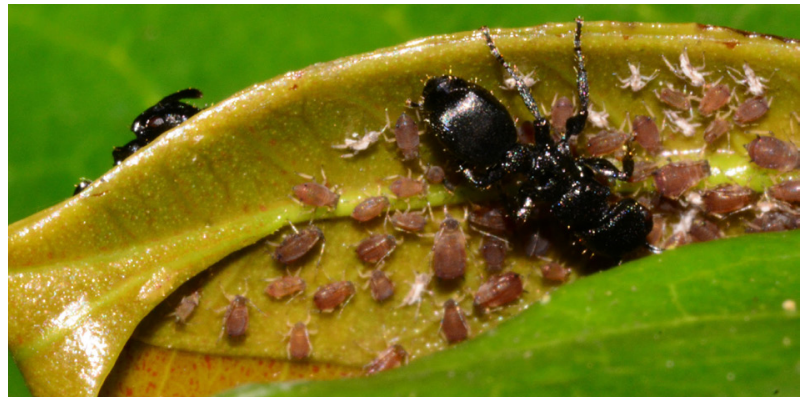

Autor: Ricardo Martínez

Fecha: 10 de abril de 2017 


\section{Reproducción}

Es interesante entender cómo se reproducen los insectos y las formas diversas en las que ocurre dicho proceso. En estas fotografías podemos observar la cópula de las especies Neolema sp. (imagen A) y Chalepus sp. (imagen B), que puede durar minutos, horas e incluso días.

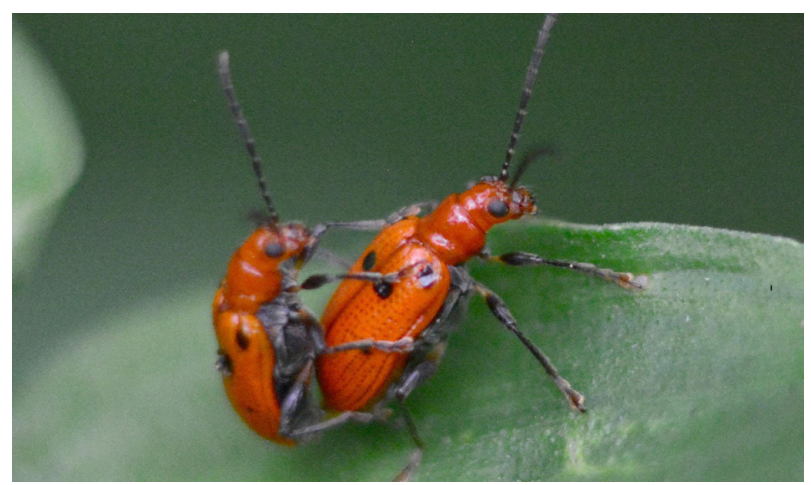

Autor: Ricardo Martínez

Fecha: 5 de noviembre de 2016

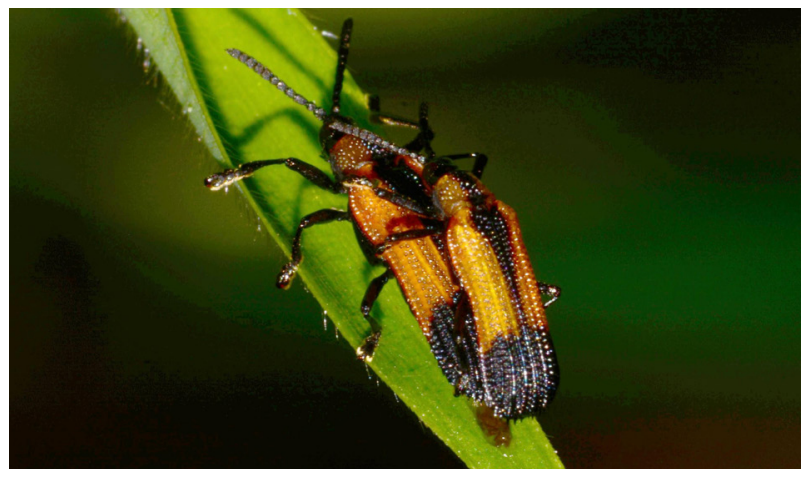

Autora: Lorena Guerrero

Fecha: 12 de noviembre de 2016

\section{Agradecimientos}

Queremos agradecer a los dueños de las fincas (doña Flor Sánchez, Efrén Sánchez, don Euclides y don Julio Castro); a los colegas Óscar Javier Cadena Castañeda y Andrés David Murcia, de la Universidad Distrital Francisco José de Caldas, por la colaboración para la identificación y corroboración de los Ortópteros y Fásmidos. También, a Bolívar Rafael Garcete Barrett, del Museo Nacional de Historia Natural del Paraguay por la identificación de avispas; a Michel Camilo Bejarano A, del ICN, Universidad Nacional de Colombia, sede Bogotá, por la determinación y corroboración de Lepidópteros; y finalmente a Jorge Ari Noriega, del National Museum of Natural Sciences, de Madrid, España, por la identificación de Coleópteros.

\section{Referencias}

Alcaldía de Quipile. (2012). Plan De desarrollo Municipal de Quipile, Cundinamarca, 2012-2015. [Información pública electrónica]. Recuperado de http://www.quipile cundinamarca.gov.co.

Blas, M. y Del Hoyo, J. (2013). Entomología cultural y conservación de la biodiversidad. Los insectos en las Artes Mayores. Cuadernos de Biodiversidad, 42, 1-22.

Cadena-Castañeda, O. J. y Cardona, G. J. M. (2017). Studies in Colombian Caelifera and Adjacent Territories: Ciglianacris, A New Genus of Anden Melanoplinae (Orthoptera: Acrididae). Zootaxa, 4286(2), 267-276. DOI: 10.11646/zootaxa.4286.2.9.

Martínez R. M. (2018). Relaciones socioecológicas entre hormigas y agricultores como estrategia sustentable en cafetales de sombrío (Quipile, Cundinamarca) (tesis de maestría). Universidad Distrital Francisco José de Caldas, Bogotá, Colombia. Recuperado de http://hdl.handle.net/11349/13173.

Pérez, M. (2012). La fotografía macro explicada al detalle. Recuperado de: http://www.blogdelfotografo. com/fotografia-objetivos-macro/

Perfecto, I.; Vandermeer, J.; Philpott, S. M. (2010). Complejidad ecológica y el control de plagas en un cafetal orgánico: develando un servicio ecosistémico autónomo. Agroecología, 5, 41-51.

Rodríguez, N.; Armenteras, D.; Morales, M. y Romero, M. (2006). Ecosistemas de los Andes colombianos (2. ${ }^{a}$ edición). Instituto de Investigación de Recursos Biológicos Alexander von Humboldt.

Schoonhoven, L.M.; Van Loon, J. A. y Dicke, M. (2005).. Insect-plant biology (2. ${ }^{a}$ edición). Nueva York: Oxford University Press. .

Sistema Integrado de Biodiversidad (SIB) Colombia, (2016). Biodiversidad en cifras. Recuperado de http://www.sibcolombia.net/ biodiversidad-en-cifras/.

Sinisterra, R. M.; Gallego-Ropero, M.C.; Armbrecht, I. (2016). Hormigas asociadas a nectarios extraflorales de árboles de dos especies de Inga en cafetales de Cauca, Colombia. Acta Agronómica, 65 1), 9-15.

Stadler, B., Dixon, T. (2008). Mutualism: Ants and their insect partners. Nueva York: Cambridge University Press.

Torres, K. (2014). La observación e ilustración de insectos como una estrategia para el reconocimiento y valoración de lo vivo (tesis de pregrado). Universidad Pedagógica Nacional, Bogotá, Colombia.

Wolff, M. (2006). Insectos de Colombia, Guía básica de familias. Medellín: Laboratorio de Colecciones Entomológicas. Universidad de Antioquia. 
